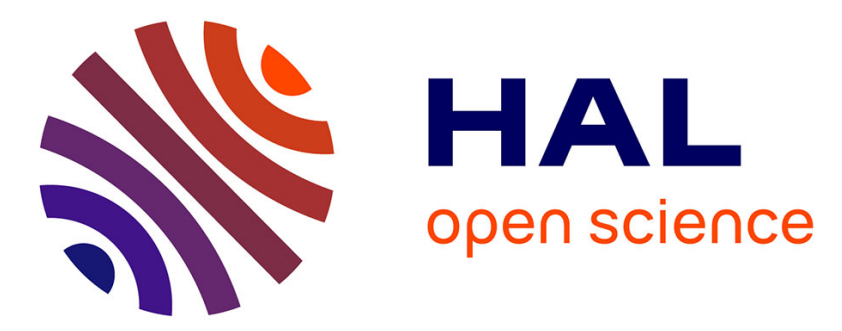

\title{
Alkyne-Tagged Analogue of Jaspine B: New Tool for Identifying Jaspine B Mode of Action
}

Alexandrine Rozié, Cecile Santos, Isabelle Fabing, Patrick Calsou, Sébastien Britton, Yves Génisson, Stéphanie Ballereau

\section{- To cite this version:}

Alexandrine Rozié, Cecile Santos, Isabelle Fabing, Patrick Calsou, Sébastien Britton, et al.. AlkyneTagged Analogue of Jaspine B: New Tool for Identifying Jaspine B Mode of Action. ChemBioChem, 2018, 19 (23), pp.2438-2442. 10.1002/cbic.201800496 . hal-02059233

\section{HAL Id: hal-02059233 https://hal.science/hal-02059233}

Submitted on 23 Mar 2021

HAL is a multi-disciplinary open access archive for the deposit and dissemination of scientific research documents, whether they are published or not. The documents may come from teaching and research institutions in France or abroad, or from public or private research centers.
L'archive ouverte pluridisciplinaire HAL, est destinée au dépôt et à la diffusion de documents scientifiques de niveau recherche, publiés ou non, émanant des établissements d'enseignement et de recherche français ou étrangers, des laboratoires publics ou privés. 


\title{
Alkyne-tagged analogue of jaspine B: new tool for identifying jaspine $B$ mode of action
}

\author{
Alexandrine Rozié,${ }^{[b]}$ Cécile Santos,${ }^{[a]}$ Isabelle Fabing, ${ }^{[a]}$ Patrick Calsou, ${ }^{[b]}$ Sébastien Britton, ${ }^{*[b]}$ Yves \\ Génisson $^{[\mathrm{a}]}$ and Stéphanie Ballereau* ${ }^{* a]}$
}

\begin{abstract}
The first biologically relevant clickable probe related to the antitumor marine lipid jaspine $B$ is reported. Concise synthetic route to both enantiomers relied on the chiral SCF enantiomeric resolution of racemic materials. The eutomeric dextrogyre derivative represents the first jaspine $\mathrm{B}$ analogue with enhanced cytotoxicity with $\mathrm{IC}_{50}$ down to $30 \mathrm{nM}$. These enantiomeric probes revealed a chiralitydependent cytoplasmic imaging of U2OS cancer cells by in situ click labelling.
\end{abstract}

Jaspine B, also known as pachastrissamine (Fig 1), is a natural anhydrophytosphingosine isolated independently from two different marine sponges, Jaspis $s p .{ }^{[1]}$ and Pachastrissa sp. ${ }^{[2]}$ respectively.

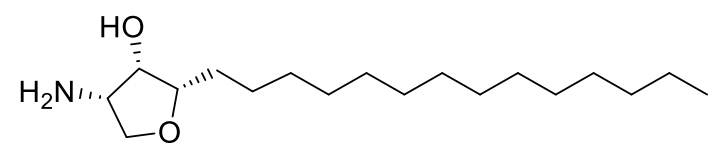

Figure 1. Jaspine B (Pachastrissamine)

This marine lipid exhibits an in vitro cytotoxicity with $\mathrm{IC}_{50}$ in the low micromolar range against a large panel of cancer cell lines. ${ }^{[3]}$ In order to gain insights into jaspine $B$ antitumor behaviour, biological studies aiming at exploring its cellular mechanism of action were undergone. In 2009, Canals et al. correlated the cytotoxicity of jaspine $B$ in lung carcinoma cells with dihydroceramide-mediated autophagy. ${ }^{[4]}$ Simultaneously, our group reported that jaspine $B$ triggers apoptotic cell death in melanoma cells though blockage of sphingomyelin biosynthesis and accumulation of cellular ceramide. ${ }^{[5]}$ Two years later, Yoshimitsu et al. described jaspine B and its stereoisomers as moderate to potent in vitro inhibitors of sphingosine kinases (SphK1 and SphK2). ${ }^{[6]}$ Yoo et al. also investigated the antimelanoma activity of jaspine $B$ and proposed that it is a result of the inhibition of ERK-mediated $\mathrm{FOXO} 3$ downregulation and decreased Cdk2 levels. ${ }^{[7]}$ In 2014, we have also reported Jaspine $B$ as a potential inhibitor of the ceramide trafficking protein CERT which mediates ceramides transfer from the

[a] Dr. S. Ballereau, Dr. C. Santos, I. Fabing, Dr. Y. Génisson. SPCMIB, UMR5068 CNRS-Université Paul Sabatier-Toulouse III, 118 route de Narbonne, Toulouse, F-31062, France. E-mail: ballereau@chimie.ups-tlse.fr

[b] Dr. S. Britton, Dr. P. Calsou, A. Rozié. Institut de Pharmacologie et de Biologie Structurale, UMR5089 CNRS-Université de Toulouse, Equipe Labellisée Ligue Nationale contre le Cancer 2018, 31077 Toulouse, France. E-mail: sebastien.britton@ipbs.fr

Supporting information for this article is given via a link at the end of the document endoplasmic reticulum to the Golgi. ${ }^{[8]}$ Very recently, Cingolani et al. disclosed that jaspine $B$ induces non-apoptotic cell death in gastric cancer cells independently from its inhibition of ceramide synthase. ${ }^{[9]}$

Despite this recurrent interest in the likely multi-target jaspine B antitumor mode of action, underlying molecular mechanisms have not yet been deciphered. So as to deepen the understanding of the jaspine $B$ cytotoxic behaviour, novel pharmacological tools are needed. We are reporting here the design, total synthesis and first use for in cellulo imaging of unprecedented jaspine B-related chemical probes.

Numerous syntheses of jaspine B and analogues were reported in the literature. ${ }^{[3,10]}$ Yet, surprisingly, no molecular probes deriving from this antitumour anhydrophytosphingosine have been disclosed to date. In order to explore this track, we first focused on the development of fluorophore-labelled derivatives. Comparative evaluation of all jaspine B structural analogues allowed delineation of several key structure-activity trends. The all-S stereochemistry of the tetrahydrofuran core is crucial for the cytotoxic activity ${ }^{[11]}$ as is the presence of the 1,2-aminoalcohol moiety. ${ }^{[9,12]}$ On the other hand, modifications of the aliphatic chain, including in the terminal position, are reasonably well tolerated. ${ }^{[12 b, 13]}$ On this basis, we envisioned jaspine Brelated probes bearing a fluorescent tag at the terminus of the alkyl chain so as to minimize its impact on the biological behaviour. In order to ensure a synthetic flexible access to these probes, we choose to synthetize an $\omega$-ethynyl jaspine B derivatives allowing a late introduction of the fluorophoric moiety through a copper-catalysed azide-alkyne cycloaddition (CuAAC) reaction (Fig 2).

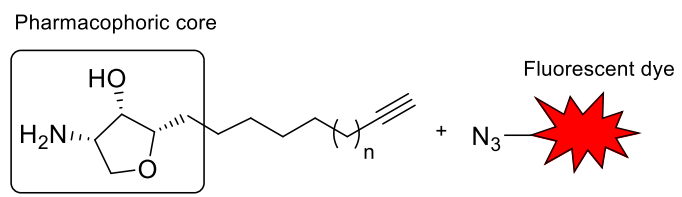

Alkyne-tagged jaspine $B$

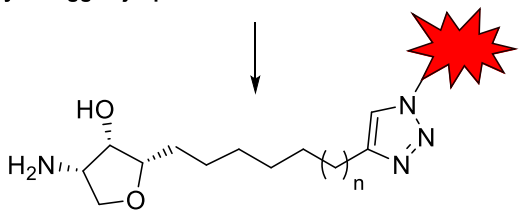

Figure 2. Jaspine B probe.

The advantages of this biorthogonal click reaction have no longer to be demonstrated and its range of applications in chemical biology fully illustrates the scope of this transformation. ${ }^{[14]}$ 
Besides the fact that several azide-functionalized clickable fluorescent probes are commercially available to be engaged in the CuAAC click reaction with a $\omega$-ethynyl jaspine $B$, such a strategy allows advantageously to introduce the fluorophoric group either at the end of the chemical synthesis or upon cell treatment with the acetylenic probe itself. The marginal structural modification introduced by the alkyne moiety at the extremity of the alkyl chain is indeed expected to minimize the impact on cell penetration, localization and biological activity as it was already observed for various terminal acetylenic lipids. ${ }^{[15]}$

Bearing in mind that the overall length of the aliphatic backbone has a significant impact on jaspine B cytotoxicity, ${ }^{[12 b, 16]}$ we targeted $\omega$-alkyne-tagged analogues with two different lipidic chains: one presenting the same overall length (C14) as the natural compound and another one with the clickable alkyne tag added to the native jaspine $B$ aliphatic tail (C16). These analogues were first prepared in racemic series according to a concise synthetic pathway we initially developed for the total synthesis of jaspine B. ${ }^{[11 b]}$ This approach can also provide a practical access to both enantiomers of the targeted analogues through enantiomeric resolution of racemic materials.

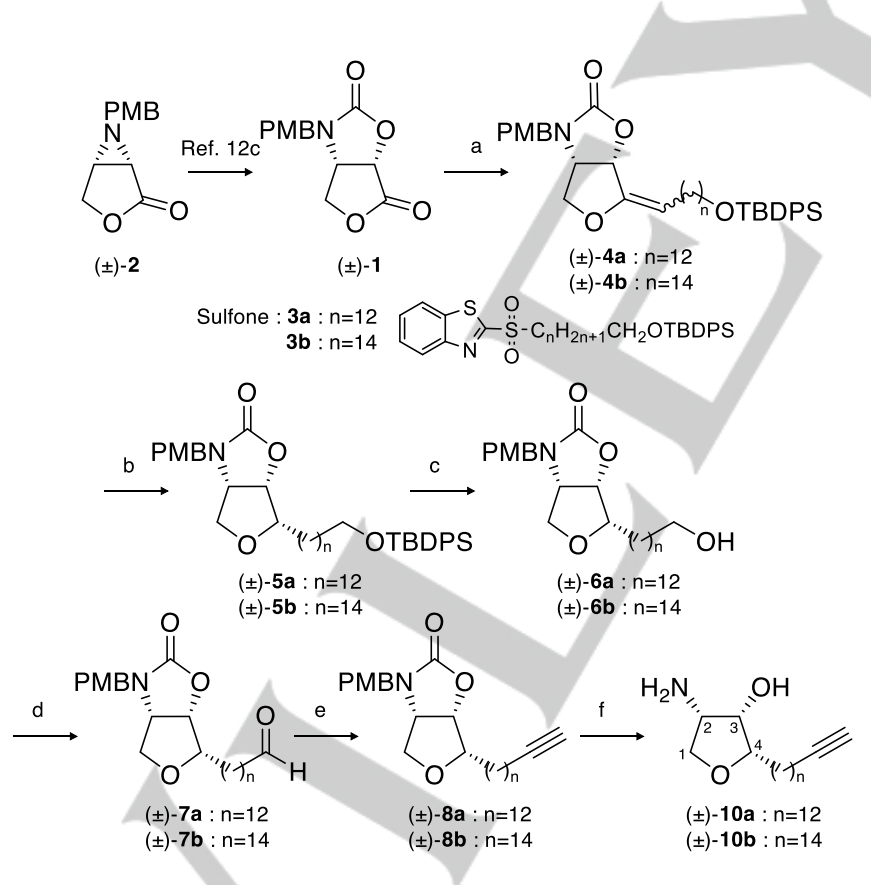

Scheme 1. Synthesis of $\omega$-ethynyl jaspine $B$ analogues $( \pm)-10 \mathbf{a}$ and $( \pm)-10 \mathbf{b}$. Reagents and conditions: a) Sulfone $\mathbf{3 a}$ or $\mathbf{3} \mathbf{b}$, LiHMDS, THF then DBU, THF, ( \pm -4a: $43 \%,( \pm)-\mathbf{4 b}: 72 \%, E / Z 2: 1 ;$ b) $\mathrm{H}_{2},\left(\mathrm{PPh}_{3}\right) \mathrm{RhCl}, \mathrm{C}_{6} \mathrm{H}_{6}, \mathrm{EtOH},( \pm)-5 \mathrm{a}: 88 \%$ ( \pm -5b: $90 \%$; c) TBAF, THF, ( \pm )-6a: $75 \%$, ( \pm )-6b: quant.; d) DMP, $\mathrm{CH}_{2} \mathrm{Cl}_{2}$, ( \pm -7a: $98 \%$, ( \pm -7b: $84 \%$; e) Bestmann-Ohira reagent, $\mathrm{MeOH},( \pm)-8 \mathrm{a}: 93 \%$, ( \pm )-8b: $98 \%$; f) i) $\mathrm{CAN}, \mathrm{CH}_{3} \mathrm{CN}: \mathrm{H}_{2} \mathrm{O},( \pm)-9 a: 70 \%$, ( \pm -9b: $99 \%$; ii) $\mathrm{KOH}, \mathrm{EtOH} /$ $\mathrm{H}_{2} \mathrm{O},( \pm)-10 \mathrm{a}: 60 \%,( \pm)-10$ b: $89 \%$.

The lactone oxazolidinone 1 (Scheme 1), obtained from 2,3aziridino- $\gamma$-lactone $2{ }^{[12 c]}$ was submitted to a Julia modified olefination with the $\omega$-functionalized sulfones $\mathbf{3 a}$ or $\mathbf{3 b},{ }^{[17]}$ to give 4a and $\mathbf{4 b}$, respectively. Diastereoselective hydrogenation delivered in turn the fully protected intermediates $\mathbf{5 a}$ and $\mathbf{5 b}$. The terminal alcohol was then deprotected and oxidized into an aldehyde to give $\mathbf{7 a}$ and $\mathbf{7 b}$. Homologation into the expected terminal alkyne was ensured by means of the Bestmann-Ohira reagent. ${ }^{[18]}$ Deprotection of the 1,2-aminoalcohol moiety then relied on the oxidative cleavage of the PMB-group (giving ( \pm )-9a and $( \pm)-9 b)$ followed by the hydrolysis of the oxazolidinone ring to offord the targeted $\omega$-ethynyl jaspine B ( \pm )-10a and $( \pm)-10 b$.

In order to assess the influence of the terminal alkyne tag on biological behavior of these new jaspine $B$ analogues, their cytotoxicity was first evaluated and compared to that of the synthetic racemic jaspine $B .{ }^{[11 b]}$

The viability of U2OS (human osteosarcoma) cells was measured as previously described ${ }^{[19]}$ in the presence of $( \pm)$-jaspine $\mathrm{B},( \pm)-\mathbf{1 0 a}$ and $( \pm)-\mathbf{1 0 b}$. The two clickable analogues $( \pm)-10 \mathrm{a}$ and $( \pm)-10 \mathrm{~b}$ exhibit an $\mathrm{IC}_{50}$ value of $56 \mathrm{nM}$ and $60 \mathrm{nM}$, respectively (Table 1$)$, significantly lower than that of $( \pm$ )-jaspine B $\left(\mathrm{IC}_{50} 186 \mathrm{nM}\right)$. This finding supports the assumption that introducing an alkyne unit at the end of the anhydrophytoshingosine alkyl chain does not indeed significantly alter the biological activity of the resulting probe.

Table 1. Cytotoxicity of $( \pm)$-jaspine $B,( \pm)-10 a$ and $( \pm)$-10b on U2OS cells; IC 50 are calculated using GraphPad Prism 5.

\begin{tabular}{|c|c|c|c|}
\hline Compound & ( \pm )-Jaspine B & $( \pm)-10 a$ & $( \pm)-10 b$ \\
\hline $\mathrm{IC}_{50}(\mu \mathrm{M})$ & 0.186 & 0.056 & 0.060 \\
\hline $\begin{array}{c}\text { 95\% confidence } \\
\text { interval }\end{array}$ & $0.168-0.207$ & $0.050-0.063$ & $0.057-0.064$ \\
\hline $\mathrm{n}=$ & 4 & 4 & 4 \\
\hline
\end{tabular}

We then tackled the preparation of enantiopure materials. The $\omega$-ethynyl jaspine B $( \pm)-10 b$ bearing a homologated $\mathrm{C} 16$ lipidic chain was selected on the basis of the commercial availability of the corresponding starting pentadecanol. The enantiomeric resolution was carried out on the racemic mixture of protected analogue $( \pm)-\mathbf{8 b}$ by means of semipreparative supercritical fluid chromatography (SFC) using a Chiralpak IC column (5 mm silica particles immobilized with cellulose tris-(3,5dichlorophenylcarbamate)) eluted with $20 \%$ of a $\mathrm{CH}_{2} \mathrm{Cl}_{2} / \mathrm{MeOH}$ mixture $(80: 20, v / v)$ as an additive in a $\mathrm{CO}_{2}$ mobile phase. Both enantiomers were obtained in $88 \%$ yield and with an enantiomeric purity $>99.5 \%$ according to its re-analysis by chiral SCF (see ESI). The all-S absolute configuration was assigned to the dextrogire enantiomeric sample on the basis of the parent jaspine $B$.

Each enantiomer of the protected $\omega$-ethynyl jaspine $B$ analogue $(+)-\mathbf{8 b}$ and $(-)-\mathbf{8 b}$ was in turn individually submitted to the two steps deprotection protocol leading to (+)-10b and (-)-10b (Scheme 2). 


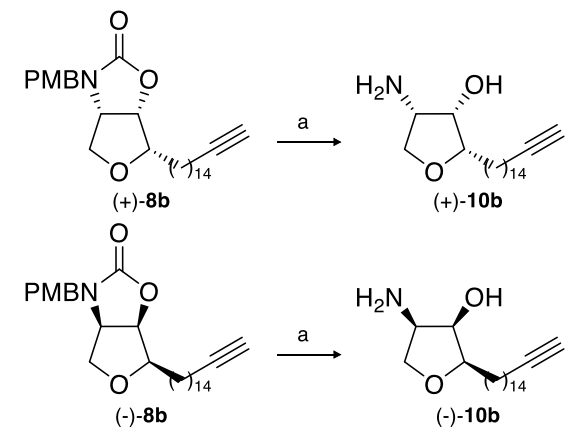

Scheme 2. Synthesis of $\omega$-ethynyl analogues of jaspine $B$ and ent-jaspine $B$. Reagents and conditions: a) i) $\mathrm{CAN}, \mathrm{CH}_{3} \mathrm{CN}: \mathrm{H}_{2} \mathrm{O},(+)-9 b: 67 \%,(-)-9 b: 84 \%$; ii) $\mathrm{KOH}, \mathrm{EtOH} / \mathrm{H}_{2} \mathrm{O},(+)-10 \mathrm{~b}: 79 \%,(-)-10 \mathrm{~b}: 67 \%$.

The cytotoxicity of each enantiomer of $\omega$-ethynyl jaspine $B$ $(+)-10 b$ and $(-)-10 b$ was evaluated in U2OS cells and compared with those of natural (+)-jaspine $B$ and its synthetic enantiomer (-)-jaspine B (Table 2).

Table 2. Cytotoxicity of (+)-jaspine B, (-)-jaspine $B,(+)-10 b$ and (-)-10b on U2OS cells ; $\mathrm{IC}_{50}$ are calculated using GraphPad Prism 5 ..

\begin{tabular}{ccccc}
\hline Compound & $(+)$-Jaspine B & $(-)$-Jaspine B & $(+)-10 b$ & $(-)-10 b$ \\
\hline $\begin{array}{c}\text { IC } 50(\mu \mathrm{M}) \\
95 \%\end{array}$ & 0.109 & $\mathbf{2 . 2 9 8}$ & $\mathbf{0 . 0 3 4}$ & $\mathbf{1 . 5 3 2}$ \\
$\begin{array}{c}\mathbf{9 5 \%} \\
\text { confidence } \\
\text { interval } \\
\mathbf{n}=\end{array}$ & $0.102-0.116$ & $2.117-2.494$ & $0.031-0.038$ & $1.394-1.685$ \\
\hline
\end{tabular}

In coherence with what is observed for the natural product and its enantiomer, the absolute configuration of the $\omega$-ethynyl jaspine $B$ analogues proved to be determinant for the cytotoxicity. The dextrogyre $(S, S, S)-\mathbf{1 0 b}$ corresponds to the eutomer that, in addition, displays a significantly superior potency than its enantiomer (eudismic ratio 0.025 ). Of note is also the fact that $(+)-10 \mathrm{~b}$ is 3.2 times more cytotoxic than the synthetic sample of natural $(+)$-jaspine $B$. There is indeed, to the best of our knowledge, no precedent report of an analogue of jaspine $B$ with enhanced cytotoxicity.

As mentioned earlier, the CuAAC click reaction is orthogonal enough to tolerate many functional groups. We thus envisaged performing this reaction with the totally unprotected analogue 10b. However, our first attempts to introduce a fluorophore by means of a CuAAC reaction between the terminal alkyne group of $10 \mathrm{~b}$ and an azide-tagged fluorescent probe proved troublesome. The reaction under standard conditions (catalytic $\mathrm{CuSO}_{4}$ with sodium ascorbate as reducing agent) gave no transformation. The use of an over-stoichiometric amount of $\mathrm{Cu}(\mathrm{I})$ (2 eq. of $\mathrm{Cul}$ ) in the presence of a copper ligand tris[(1benzyl-1H-1,2,3-triazol-4-yl)methyl]amine (2 eq. of TBTA) over a prolonged reaction time $(>48 \mathrm{~h})$ were necessary to form the expected cycloadducts. As a representative example, 10b was engaged in a CUAAC reaction with azido derivatives of NBD or pyrene (Scheme 3 and ESI). Yet, the expected click reaction products were only obtained with moderate yields $(<50 \%)$ and revealed surprisingly unstable. These disappointing results further prompted us to exploit the in situ click labelling approach.

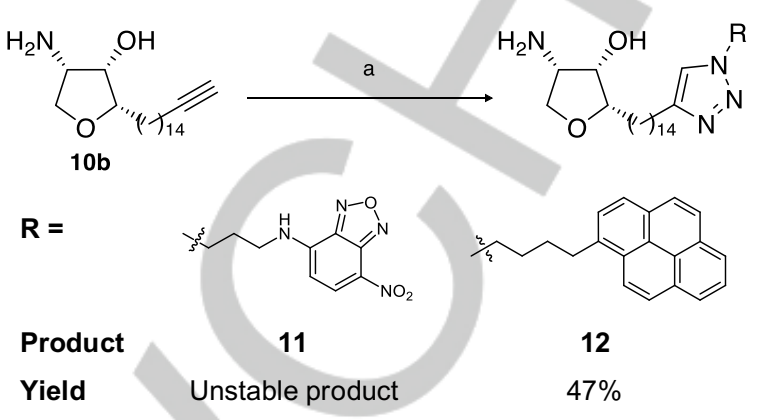

Scheme 3. CuAAC click reaction of 10b. Reagents and conditions: a) Cul (2 eq.) $\mathrm{N}, \mathrm{N}$-diisopropylethylamine (DIPEA, 2 eq.), tris[(1-benzyl-1H-1,2,3-triazol4-yl)methyl]amine (TBTA, 2 eq.), $\mathrm{N}_{3}-\mathrm{R}$ (1 eq.), $48 \mathrm{~h}$.

To reveal the subcellular distribution of jaspine $B$, we analyzed the subcellular distribution of (-)-10b and (+)-10b in U2OS cells. U2OS cells are derived from a human osteosarcoma, a rare pediatric cancer for which treatments are limited. U2OS are characterized by large nucleus and cytoplasm and have therefore been extensively used for analyzing the subcellular distribution of clickable small molecules in several studies. ${ }^{[20]}$ Furthermore, reference pictures of U2OS cells subcellular compartments, obtained through the Cell Paitning assay, ${ }^{[21]}$ are available from the Broad Institute Image Cell Library ${ }^{[22]}$ facilitating the analysis of patterns observed in these cells. U2OS cells were treated $2 \mathrm{~h}$ with $0.5 \mu \mathrm{M}(+)-10 \mathrm{~b},(-)-10 \mathrm{~b}$ or with the vehicle alone and fixed the cells with $2 \%$ paraformaldehyde. After permeabilization with $0.2 \%$ (v:v) Triton X-100, the CuAAC reaction was performed in situ with an azido-AlexaFluor 594 fluorophore, as described previously. ${ }^{[20 a, 23]}$ This experiment revealed a different distribution of $(+)-10 b$ and $(-)-10 b$ in cells (Fig 3). 


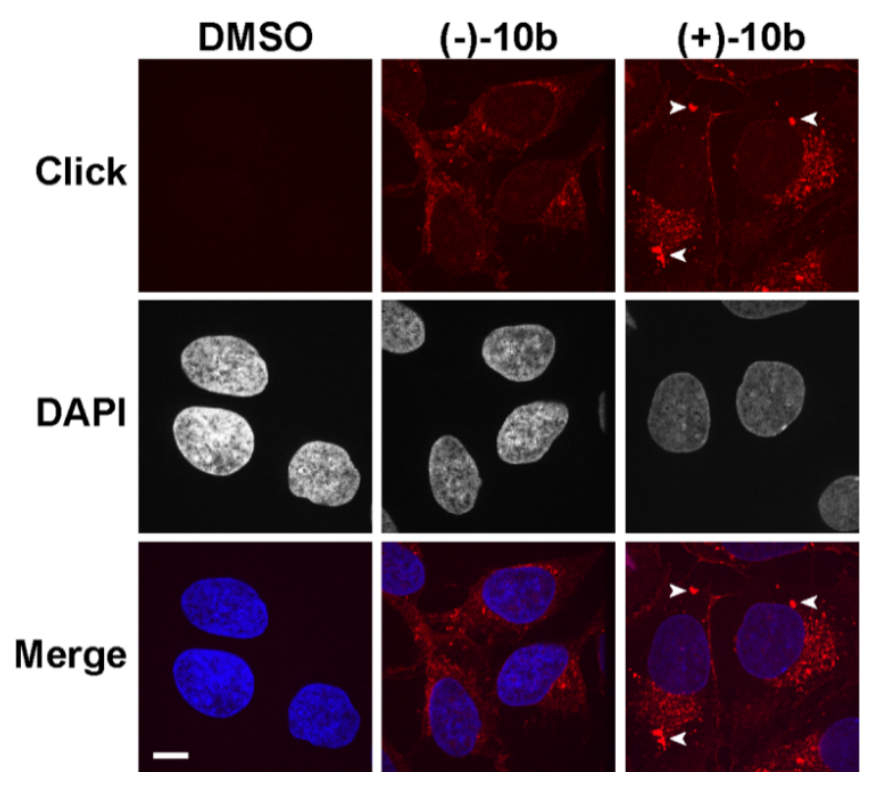

Figure 3. Imaging (+)-10b and (-)-10b distribution in U2OS cells. Post-fixation in situ CuAAC-mediated ligation of an azido-AlexaFluor 594 was used to reveal the cellular distribution of the clickable probes. White arrows indicate cytoplasmic aggregates. The white scale bar corresponds to 10 microns.

Compound (-)-10b showed a weak cytoplasmic staining evocative of endoplasmic reticulum. In addition to a similar but brighter pattern, the eutomer (+)-10b formed large and intense aggregates in the cytoplasm of treated U2OS cells. A similar subcellular distribution of (-)-10b and (+)-10b was observed using A549 cells (see ESI). A549 cells are derived from a human lung cancer, are characterized by large nucleus and cytoplasm facilitating imaging and their subcellular compartments have also been analyzed through the Cell Painting assay. ${ }^{[21]}$ To confirm that the pattern observed with the clickable analogue $(+)-10 b$ reflects the $(+)$-jaspine $B$ distribution, we performed a competition experiment on living cells by co-incubating the (+)$10 \mathrm{~b}$ with a 20 -fold excess of (+)-jaspine $B$. As shown on figure 4 , the cytoplasmic aggregates observed with $(+)-10 b$ are lost when $(+)-10 b$ is incubated with an excess of non clickable natural $(+)-$ jaspine $B$. Together these results strongly support that $(+)-10 b$ can be used as a surrogate to analyze jaspine $B$ subcellular distribution and to clarify the elusive mechanism of action of this potential anticancer agent.

We disclosed here the first design and synthesis of biologically relevant clickable analogues of jaspine B. In contrast to previously reported analogues of jaspine $B,{ }^{[3]}$ our clickable derivatives present a cytotoxic activity superior to the natural anhydrophytosphingosine. Taking advantage of these clickable probes, we established that jaspine $B$ accumulates in the cytoplasm of human cells in vesicular structures and forms large aggregates. The nature of these aggregates and their relationship with jaspine B cytotoxic activity await further investigations. The potential use of the reported enantiomeric clickable probes in a chemoproteomic target identification approach will also be explored in due course.

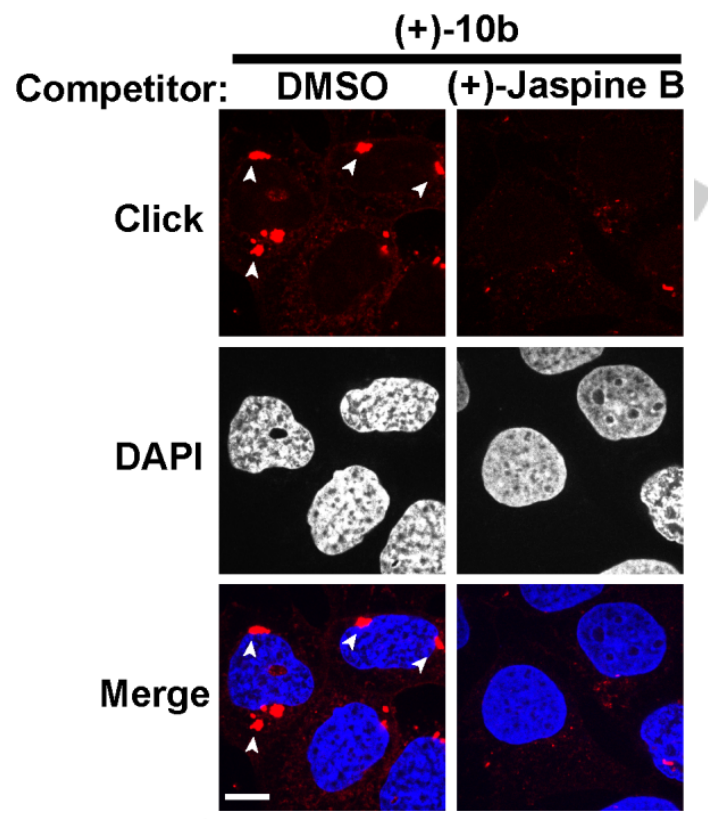

Figure 4. Competing (+)-10b staining with (+)-jaspine B. U2OS cells were treated $2 \mathrm{~h}$ with $0.5 \mu \mathrm{M}(+)-10 \mathrm{~b}$ alone, as a reference, or together with $10 \mu \mathrm{M}$ (+)-jaspine B, corresponding to a 20 -fold excess. Post-fixation in situ CuAACmediated ligation of an azido-AlexaFluor 594 was used to reveal the cellular distribution of $(+)-10 b$. White arrows indicate cytoplasmic aggregates. The white scale bar corresponds to 10 microns.

\section{Acknowledgements}

This research was funded by an "Emergence" grant from Cancéropôle Grand Sud-Ouest. Research in the Calsou's laboratory is supported by Ligue Nationale contre le Cancer (Programme Labellisation 2018).

We thank the "Institut de Chimie de Toulouse (ICT, FR2599)» for providing access to SFC equipment.

We are grateful to the members of the IPBS-TRI Core Imaging Facility in particular Antonio Peixoto and Serge Mazeres for excellent technical assistance. We thank the Région Occitanie and the French Research Ministry for their financial support to the imaging facility.

Keywords: JaspineB $\cdot$ Pachastrissamine $\cdot$ Fluorescent probe • Click chemistry $\cdot$ Bioorthogonality

[1] V. Ledroit, C. Debitus, C. Lavaud and G. Massiot, Tetrahedron Lett 2003, 44, 225-228.

[2] I. Kuroda, M. Musman, I. I. Ohtani, T. Ichiba, J. Tanaka, D. G. Gravalos and T. Higa, J. Nat. Prod. 2002, 65, 1505-1506.

[3] M. Martinková and J. Gonda, Carbohydr. Res. 2016, 423, 1-42.

[4] D. Canals, D. Mormeneo, G. Fabrias, A. Llebaria, J. Casas and A. Delgado, Bioorg. Med. Chem. 2009, 17, 235-241.

[5] Y. Salma, E. Lafont, N. Therville, S. Carpentier, M. J. Bonnafe, T. Levade, Y. Génisson and N. Andrieu-Abadie, Biochem. Pharmacol. 2009, 78, 477-485.

[6] Y. Yoshimitsu, S. Oishi, J. Miyagaki, S. Inuki, H. Ohno and N. Fujii, Bioorg. Med. Chem. 2011, 19, 5402-5408.

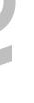


[7] H. Yoo, Y. S. Lee, S. Lee, S. Kim and T. Y. Kim, Phytotherapy Res. 2012, 26, 1927-1933.

[8] C. Santos, F. Rodriguez, V. Garcia, D. Moravcikova, D. Berkes, A. Daich, T. Levade, C. Baudoin-Dehoux, S. Ballereau and Y. Génisson, Chembiochem 2014, 15, 2522-2528.

[9] F. Cingolani, F. Simbari, J. L. Abad, M. Casasampere, G. Fabrias, A. H. Futerman and J. Casas, J. Lipid Res. 2017, 58, 1500-1513.

[10] a) S. Ballereau, M. Baltas and Y. Génisson, Curr. Org. Chem. 2011, 15, 953-986; b) E. Abraham, S. G. Davies, P. M. Roberts, A. J. Russell and J. E. Thomson, Tetrahedron: Asymmetry 2008, 19, 1027-1047.

[11] a) M. Martinková, E. Mezeiová, M. Fabišíková, J. Gonda, M. Pilátová and J. Mojžiš, Carbohydr. Res. 2015, 402, 6-24; b) C. Santos, I. Fabing, N. Saffon, S. Ballereau and Y. Génisson, Tetrahedron 2013, 69, 72277233; c) G. Jayachitra, N. Sudhakar, R. K. Anchoori, B. V. Rao, S. Roy and R. Banerjee, Synthesis 2010, 115-119.

[12] a) S. Pashikanti, R. Ukani, S. A. David and A. Datta, Synthesis 2017, 49, 2088-2100; b) Y. Salma, S. Ballereau, S. Ladeira, C. Lepetit, R. Chauvin, N. Andrieu-Abadie and Y. Génisson, Tetrahedron 2011, 67, 4253-4262; c) S. Ballereau, N. Andrieu-Abadie, N. Saffon and Y. Génisson, Tetrahedron 2011, 67, 2570-2578.

[13] a) E. Zhang, S. Wang, J. Gao, X. J. Shi, M. M. Wang, S. M. Xu and H. M. Liu, Heterocycles 2016, 92, 2018-2031; b) J.-M. Xu, E. Zhang, X.-J. Shi, Y.-C. Wang, B. Yu, W.-W. Jiao, Y.-Z. Guo and H.-M. Liu, Eur. J. Med. Chem. 2014, 80, 593-604; c) Y. Salma, S. Ballereau, C. Maaliki, S. Ladeira, N. Andrieu-Abadie and Y. Génisson, Org. Biomol. Chem. 2010, 8, 3227-3243.

[14] P. Thirumurugan, D. Matosiuk and K. Jozwiak, Chem. Rev. 2013, 113, 4905-4979.
[15] A. Gaebler, R. Milan, L. Straub, D. Hoelper, L. Kuerschner and C. Thiele, J. Lipid Res. 2013, 54, 2282-2290.

[16] Y. Génisson, L. Lamande, Y. Salma, N. Andrieu-Abadie, C. Andre and M. Baltas, Tetrahedron: Asymmetry 2007, 18, 857-864.

[17] J. Pospíšil and H. Sato, J. Org. Chem. 2011, 76, 2269-2272.

[18] G. J. Roth, B. Liepold, S. G. Müller and H. J. Bestmann, Synthesis 2004, 2004, 59-62.

[19] V. Vichai and K. Kirtikara, Nat. Protoc. 2006, 1, 1112.

[20] a) R. Rodriguez, K. M. Miller, J. V. Forment, C. R. Bradshaw, M. Nikan, S. Britton, T. Oelschlaegel, B. Xhemalce, S. Balasubramanian and S. P. Jackson, Nat. Chem. Biol. 2012, 8, 301; b) E. Zacharioudakis, P. Agarwal, A. Bartoli, N. Abell, L. Kunalingam, V. Bergoglio, B. Xhemalce, K. M. Miller and R. Rodriguez, Angew. Chem. Int. Ed. 2017, 56, 64836487 ; c) T. T. Mai, A. Hamaï, A. Hienzsch, T. Cañeque, S. Müller, J. Wicinski, O. Cabaud, C. Leroy, A. David, V. Acevedo, A. Ryo, C. Ginestier, D. Birnbaum, E. Charafe-Jauffret, P. Codogno, M. Mehrpour and R. Rodriguez, Nat. Chem. 2017, 9, 1025.

[21] M.-A. Bray, S. Singh, H. Han, C. T. Davis, B. Borgeson, C. Hartland, M. Kost-Alimova, S. M. Gustafsdottir, C. C. Gibson and A. E. Carpenter, Nat. Protoc. 2016, 11, 1757.

[22] M.-A. Bray, S. M. Gustafsdottir, M. H. Rohban, S. Singh, V. Ljosa, K. L. Sokolnicki, J. A. Bittker, N. E. Bodycombe, V. Dančík, T. P. Hasaka, C. S. Hon, M. M. Kemp, K. Li, D. Walpita, M. J. Wawer, T. R. Golub, S. L. Schreiber, P. A. Clemons, A. F. Shamji and A. E. Carpenter, GigaScience 2017, 6, giw014-giw014.

[23] D. Larrieu, S. Britton, M. Demir, R. Rodriguez and S. P. Jackson, Science 2014, 344, 527-532. 


\section{COMMUNICATION}
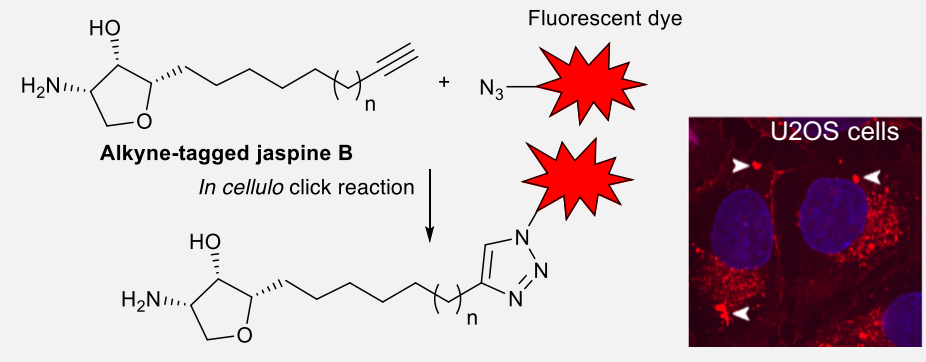

The synthesis of the first biologically relevant clickable probes related to the natural antitumor jaspine $\mathrm{B}$ is reported. These enantiomeric probes revealed a chiralitydependent cytoplasmic imaging by in cellulo click labelling.
Alexandrine Rozié, Cécile Santos, Isabelle Fabing, Patrick Calsou, Sébastien Britton, * Yves Génisson and Stéphanie Ballereau*

\section{Page No. - Page No.}

Alkyne-tagged analogue of jaspine B: new tool for identifying jaspine $B$ mode of action 